\title{
Max Horkheimer: \\ The struggle against Total Bureaucratization ${ }^{1}$
}

\section{A reference Point}

In July 1973, at the age of 78, Max Horkheimer passed away in the Swiss town of Montagnola. If not the founder, he has been at least the most important director of the Institute of Social Research at the University of Frankfurt, from which the famous name "Frankfurt School" is derived. Actually, if we can believe Habermas, who began his academic career as Adorno's assistant, there was never a Frankfurt "school" in the strict sense of the word, except of course in its first year in exile from Germany after the escape from Nazism. At any rate, Horkheimer, more than Adorno and with grater incisiveness than Marcuse and Fromm, represents a basic point of reference for an intellectual climate that has had, despite obvious limitation, a crucial influence on both Marxist and non-Marxist thought. More rigorous than Adorno, and more open to economic and practical reality than Marcuse, the cautious Horkheimer was throughout the secure point of reference, especially after his return in Frankfurt.

Yet, his "critical theory of society" never went further than its first great expression on the theme of authority and the family". All the basic elements of "critical theory" including its ambiguity, are already present in the theoretical introduction to Horkheimer's essay, Authority and the Family: the centrality of the concept of authority; the family as the privileged sphere for the social reproduction of consensus; the human acceptance of the harshest, most intolerable conditions as if they were natural and therefore unchangeable; the need to take a methodological position allowing a global vision of the human situation, rather than a compartmentalized one; the critique of techno-formal rationality as it ignores science as a human enterprise. These ideas are born proudly finished, complete, perfect; the works that will follow, such as The Dialectic of Enlightenment (co-authored with Adorno) and The Eclipse of Reason can be considered deep, if not brilliant, extensions of the original work, but nothing more than that. For this reason, right - wing attempts to appropriate the later Horkheimer by using a few of his phrases out of context or by headlining an interview with sensational formulations, freely transcribed and interpreted, would seem at best arbitrary and misleading. No doubt, Horkheimer himself fell victim to such practices, even though, he long ago denounced the manipulatory approach of contemporary journalism. ${ }^{3}$

\footnotetext{
${ }^{1}$ A first shorter version has been published by Telos Press Publishing. F. Ferrarotti, The strugle against total burocratization, Spring 1976.

${ }^{2}$ Autorität und Familie (Paris, 1956).

${ }^{3}$ Eclipse of Reason, (New York, 1947)
} 
But a return to the texts themselves would restore totally his extraordinary intellectual and historical stature. What inspires him in his awareness of the links between the historical situation, the economic structure and the conscious attitudes of human beings living in society? It is regrettable that this global scheme could not be complemented by an effective sociology that could incorporate methodically controlled and politically oriented field work. Horkheimer did not have the tools, nor the disposition to do so, attached as he to a typically nineteenth century intellectual perspective.

\section{Authority, the Family, and the Social Reproduction of Consensus}

The key concepts on which Horkheimer's essay in Autorität und Familie turns, are: "culture," "authority," and "family." The novelty of this approach consists in the fact that a strictly speculative and highly abstract investigation does not seek to justify its own propositions by purely theoretical arguments, but rather through historical reality. Here, the concept of culture is clearly distinguished from its purely philosophical meaning as a complex of shared and co- lived experiences and values. In this sense Horkheimer can affirm that "both the subjectivist- anthropological and objectivist modes of viewing cultural institutions have their justification". But he adds that "the preservation of outmoded structures too has its source in human nature". ${ }^{4}$

He explains that by these words he does not mean an "original essence" and still less one that is "eternal or uniform". Man has no nature, but a history. For that reason, all theories that see in the movement of society a mere reflection of a "fundamental ahistorical unity" are open to criticism. Practical human attitudes and behavior are, for Horkheimer, historical realities: they follow no model of a meta-historical human nature. The fixed character of habit is based, as Max Weber would say, on the "authority of the eternal yesterday" and, though it appears as a complex of "natural" characteristics, it is nothing but the product of circumstantial historical conditions. The transformation of the given society into a more rational one, less conditioned by chance and accident, cannot be considered as something which depends on the strength of individuals. Horkheimer is convinced that the problem of individuals is not a particular problem. To hope for historical change resulting from individual effort, it means falling into resignation. Thus to accept a sterile moralistic hope. Horkheimer writes: "The relatively stable system of long-practiced, effortless behavior which men of a particular period or class manifest, the manner in which they accept their situation with the help of conscious and unconscious psychic practices, the infinitely differentiated and continuously revised structure of preferences, acts of faith, evaluations, and fantasies... This set off internal contrivances which, despite its complexity, is for the most part the daughter of necessity - all this is preserved in many instances simply because leaving the old way of life and adopting a new one, 
especially if the latter demands increased rational activity, requires strength and courage; in brief, it requires an immense psychic effort." ${ }^{5}$

Courage? Immense psychic effort? Is all this truly sufficient? Is it really only a question of psychic energy and spiritual strength? On this point Horkheimer does not offer a conclusive answer to dispel the danger of a culturalistic interpretation of social development. He simply claims that authority, particularly "faith in authority", is an instinctive historical force which is sometimes "productive" and sometimes "obstructive". Authority is a decisive, but highly ambiguous category: "A general definition of authority would necessarily be almost empty of content, but this is true of all definitions which attempt to capture elements of social life in a way that would be valid for all of history." ${ }^{6}$ The concept of authority acquires its full meaning when united to other interrelated concepts of a general theory of society not only on the analytical level, but also in the specific meaning of a precise theory, i.e., insofar as it refers to a particular historical phase and to specific forms of authority relations. This is what clarifies the contradictory character of authority for "authority as accepted dependence (...) can imply a relationship which fosters progress, is in the interests of all parties and favors the development of human powers". But it can also sum up in one word all those social relationships and ideas which have long since lost their validity, are now artificially maintained, and are contrary to the true interests of the majority. ${ }^{7}$ But authority must not be confused with authoritarianism. In this sense Horkheimer provides a broad historical summary of typical rank-relationships from the age of absolutism to bourgeois thought. Beginning with the struggle against the authority of tradition in the name of individual reason as the legitimate source of law and truth in his analysis of the social situation corresponding to late capitalism, he ends up showing that "in the present economic system society appears to be as blind as sub rational nature. Men do not use communal reflection and decision to regulate the process by which they earn their living in association with others." ${ }^{8}$ Horkheimer's conclusion contains the seeds of all later reflections in The Dialectic of Englishtenment: "The fullest possible adaptation of the subject to the reified authority of the economy is the form which reason really takes in bourgeois society." 9

This principle enunciated by Horkheimer is not new, and is almost literally connected with the Marxist formulations in The German Ideology. The intellectual who considers himself the unique and zealous repository of liberty and whom Mannheim supposes to be "free-floating" above the interests of the social classes locked in perpetual combat, the philosopher whom Husserl sees as guarding of noble values, "the true defender of

\footnotetext{
${ }^{5}$ Ibid., p. 69

${ }^{6}$ Ibid., pp. 70-71

${ }^{7}$ Ibid., p. 222.

8 Ibid., p. 83

${ }^{9}$ Ivi.
} 
humanity", all those who elaborated the universal, meta-historical worth of culture and its values, relegated to the atmosphere of a presumably "harmonious Olympus", they all get what is coming to them in Horkheimer's pages. He applies this to the intimate everyday affairs of social life. and cuts deeply into the binding, dogmatic thick skin of the social professions: "A good instance of the liberal, as he still exists in a relatively strong bourgeois community, presents a picture of freedom, openness, and good will. He knows himself to be the very opposite of a slave. Yet his sense of justice and his clarity of purpose operate within definite limits set by the economic mechanism and do not find expression in an ordering of social reality as a whole (...) He is less his own master than at the first he appears to be. His sense of personal independence and his corresponding respect for the freedom and dignity of his fellows are noble but abstract and naive as well". ${ }^{10}$ One is reminded here of Max Weber's "naivete". On the very eve of his death, even when faced with the signs of Nazi regression toward barbarity already appearing in his own civilized Bavaria, Weber remained absolutely convinced that the values of the liberal tradition were an eternal achievement. The pseudo-individualism of the great bourgeois and with it all the edifying mythology of success- "that god of the modern world" - and the self-deception of the enterpriser-demiurge, are unmasked with equal clarity.

The social institution that aids and sustains that relation founded "on an obtuse and only apparently rational authority" is, for Horkheimer, the family. It "sees to it that the kind of human character emerges which social life requires, and gives this human being in great measure the indispensable adaptability for a specific authority-oriented conduct on which the existence of the bourgeois order largely depends" ${ }^{11}$. The functions of the family are numerous and have been variously studied and interpreted. For Horkheimer they are reducible to and can be summed up in the function of stabilizing authority by constantly asserting the apparent naturalness of paternal power: "The necessity of a division and hierarchy of mankind, resting on natural, accidental, and irrational principles, is so familiar and obvious to the child that he can experience the earth and universe, too, and even the other world, only under this aspect; it is the pre-given mold into which every new impression is poured", 12 The ideas of triumph, money, power, happiness, are seen as closely interrelated. In particular, "for the formation of the authority-oriented character it is especially decisive that the children should learn, under pressure from the father, not to trace every failure back to its social causes but to remain at the level of the individual and to hypostatize the failure in religious terms as sin or in naturalistic terms as deficient natural endowment". ${ }^{13}$

\footnotetext{
${ }^{10}$ lbid., p. 92.

11 Ibid., p. 98.

12 Ibid., p. 106.

${ }^{13}$ Ibid., p. 109
} 
This should not be conceived as an explicit prescriptive pedagogical theory. If such were the case, a mere correction in education methods and in text books would be sufficient to a liberating socialization in place of an "authoritarian" one which reinforces internal and external behavior submissive to authority. Horkheimer's analysis goes deeper and implies not only the provision of intentional educational measures but also the modulation of the power of suggestion exercised by the nuclear family.

This is the central point of Franz Kafka's "Letter to his Father." It is not simply a question of teaching fathers to be "reasonable," "democratic," and "open" toward the child. A course in progressive education, or even direct experience with Montessori methods, would be inadequate for these objectives. But a study of the problem of the family as the essential instrument for reproducing authoritarianism in these terms could reduce, if not solve, these problems. In the sphere of the bourgeois nuclear family, the formation of the authoritarian personality and the exaltation of the instinct of submission are not merely the result of a narrow attitude of the parents. They are constitutive functions which can disregard the nature of education and even the will of the parents. "The child's character is formed far more by the very structure of the family than by the conscious intentions and methods of the father (...) However rationally the father may be acting by his own lights, his social position in relation to the child means that every educational measure he takes, however reasonable, must carry overtones of reward and punishment". ${ }^{14}$

Here Horkheimer's analysis is an advance beyond the limited analysis of current sociology, which is technically quite elaborate, but too narrowly circumscribed and fragmentary. The study of the family is outlined in terms of the broadest framework of global society. This approach goes beyond merely descriptive sociology (which is by definition incapable of probing the deeper significance of the social phenomena it deals with) and specialized compartmentalization (which has no way of perceiving the dialectical link between important aspects of social life considered as a whole). The consequences are "foreseeable". As long as there is no decisive change in the basic structure of social life and in the modern culture based on that structure, the family will continue to exercise its indispensable function of producing specific, authority-oriented types of character. In other words, by means of the family, society will continue to "produce" the type of men that serve it and that it needs. To solve the problem this poses for the family, society itself must be revolutionized. The crisis of the family is not an isolated crisis; it cannot be dealt with in the abstract, apart from the whole, and it cannot be described, interpreted, and solved by putting it in parentheses and 'for good reasons' omitting to consider its social roots in a scientific manner. The family is subordinated to the service and needs of society. The family 
prepares the sort of people society needs for the current mode of production: it "produces" authoritarian characters, human beings prone to attribute to their own personal talents the responsibility that ought to be ascribed to causes of a structural and social nature.

Family and society always encounter one another as antagonistic factors. The bourgeois nuclear family exalts and confirms the instinct of submission but it also values the element of love which is linked to the mother's ambiguous role: "To the extent that any principle besides that of subordination prevails in the modern family, the woman's maternal and sisterly love keeps alive a social principle dating from before historical antiquity". ${ }^{15}$ On this subject, the examination of the work of Le Play, and still more of Hegel, for whom the conflict between the family and public authority were typified by the figure of Antigone battling for her brother's corpse, and finally, the studies of Bachofen and Morgan on the death of matriarchy, are enlightening.

It is thanks to the woman and what she represents, i.e., the non-utilitarian factor that she embodies, that the present type of family still retains an anti-authoritarian dimension, unmediated by the market and separate from the logic of production. Yet, for the very same reason, the development of woman is continuously blocked by artificial obstacles; social and public life is reserved for men, and within the family woman's role involves a relation of pure dependency which has persisted through the centuries. The circle has thus come full turn. The family, which at the dawn of capitalism was always the "reproductive cell" in a rich dialectical relation with society, is now reduced to a pure instrument serving the needs of advanced industrial development, under the double profile of production and consumption. The father has become the employer.

Fromm writes about the task of exploring psychological aspects of the relation between authority and the family, including that of defining the components of the authoritarianmasochistic character. At least fifteen years before the socio psychological concept "authoritarian character" was systematically used in the investigations of Adorno, Else Frenkel-Brunswik, D.J. Levinson and R. Nevitt Sanford in The Authoritarian Personality. Fromm already dealt with its basic constitutive elements and the typical dynamism of its development.

Fromm's treatment seems particularly successful where, inspired by the work of Freud and Abraham on the "anal character," he reveals the perfect correspondence between the gratifying impulses of the authoritarian character and particular "social" virtues or values, i.e., the socially admissible and auspicious ones, such as avarice, order, scrupulousness and obstinacy, on the one hand, and the pleasure that the authoritarian character derives from the obedience and submission of another person, on the 
other. "Though the pleasure of obedience and submission as such," Fromm writes, "remain subconscious and concealed by rationalizations such as legality, necessity, reasonableness, it remains decisive for the authoritarian character that the situations in which he can obey, give him satisfaction, and when he meets them in reality he finds no need to modify them, but instead confirms them."

Fromm does not limit himself however, to a description of the explicit behavior of the authoritarian character as shaped by objective circumstances. The first part of Fromm's article is dedicated to the many aspects of authority and to the various configurations of relations between superiors and subordinates. He examines numerous situations: from the relation of the son to the father in a particular type of family structure of small rural proprietorship, to that of a woman patient with her doctor, and of the Catholic believer with his personal confessor, and 70 on. The conclusions that the bond of authority is not a strictly coercive behavior. Using a formulation advanced by Simmel, Fromm stresses that the relation to authority is the emotional bond of a subordinate to a superior person or institution.

The bond of authority, in other words, is complex. It always contains an element of fear together with an element of esteem, of admiration and love together with hatred. Fromm, following he Freudian model, understands this complexity in terms of two questions-that of mass society and that of the formation of the superego, initially designated by Freud as "the ideal self" and "the ideal of the self."

Fromm does not omit criticisms of Freud. While recognizing he great contributions of the master, he criticizes his thinking particularly for its high degree of formalism, which allows Freud to attribute to the superego all the functions that he did not intend to attribute to the ego and the id, while at the same time not distinguishing sufficiently between the various types of identification that a sharper analysis brings out. Fromm has started along the road to neo-Freudian revisionism and, though he does not fail to make use of Freud's extraordinary discoveries, he always remains quite free in applying them to particular problems.

In analyzing the dynamics of authority in the family, Fromm masterfully captures the dialectical bond by which the family is linked with the formation of the superego of the child, on the one hand, and the legitimating of authority within global society on the other. "The external power operating in society", Fromm writes, "is encountered by the child who grows up in the sphere of the patriarchal family mainly in the person of the father. By identification with the father and by internalization of his orders and prohibitions, the superego is vested with moral attributes and power. Once such an authority is established, if it corresponds with the process of identification, there is an inverse process. The superego is constantly reprojected onto the wielders of the dominant authority in society, or in the other words the individual invests effective authority with the attributes of his own superego." 
This statement of the dialectical nature of authority together with the critique of Freud, including his observation that Freud paid greater attention to the social conditioning of the father's character than any previous writer, lays the foundations for Fromm's treatment of "the social nature of personality" or "social personality". This does not mean that all is done and that theory emerges fully armed from Zeus' head like Pallas Athena. But one cannot help notice or at least foresee the indispensible premises.

Fromm's approach is essentially psychological. Starting with the Freudian definition of character not as a sum of particular traits but as a "determinate structure" for which the change of one aspect of character conditions all the others, Fromm elaborates the theory of the necessary relation between masochism and sadism. This implies that to distinguish between the two we need only to say that in one case the sadistic tendency is dominant while in the other it is censured, repressed and submerged. The masochistic tendency, according to Fromm, causes the individual to renounce the individuality of his own personality and his own happiness and to surrender to power, abolishing himself, as it were, in it, and to find pleasure and satisfaction in that dedication, which in pathological cases can reach the point of voluntary endurance of physical sufferings. The sadistic tendency has the opposite purpose of making the other person the pliant and defenseless instrument of one's own will of dominating him absolutely and totally and in extreme cases of making him suffer and express such sufferings emotionally.

The point is that sadism and masochism are always mutually inclusive and correlated, so that, it sado-masochism is censured, repressed and displaced the opposite disappears completely, but it emerges at the most diverse points, however much it conceals itself. This explains the extraordinary ambivalence of the sado-masochistic natures of authority which, while itself prostrated before greater strength, enjoys inflicting persecutions and sufferings upon the weaker. The phenomenology of the linkage and behavior of the sado-masochistic character studied by Fromm is rich and enlightening, but only rarely and sporadically does it transcend the limits of a strictly phychogical approach.

One indication of the "cultural institutionality" which reinforces faith in the "omnipotence of authority" ought to be seen in the final part of Fromm's essay, which deals with "sense of distance" as a means of presenting the bearers of authority as something special and that also functions to increase the sense of unconditional inferiority in the subordinates. Authority, which by nature is powerful and generates fear, is thus transformed into a moral model according to which submission is demanded. Typically social, and not just psychological factors, have contributed to this model. In this area, the family plays a critical role. "The child", Fromm observes, "is led to believe that its parents do not lie and that they are effectively adorned with all the moral qualities which they demand of the child... This aspect is one of the family's 
most important functions: it educates the child to consider certain moral qualities.to be connected with authority, thus contributing to the production of the authoritarian character. The child suffers one of the most serious traumas of his life when he begins to discover that his parents are in reality far from living up to their own prescriptions. But when this happens, he substitutes other authorities, such as the school".

The negative side of the predominantly psychological approach of this analysis is felt mainly in the question of the "rebellion against authority." Fromm recognizes hat however solid authority may seem, the history of both individuals and of society is "a series of rebellions." Obviously, a correct evaluation of the various types of "revolts" requires the preliminary and accurate analysis of the historical, economic and political conditions in which the event occurs. Fromm's evaluation, purely psychological and meta-historical, leaves much to be desired. The whole question of anarchy seems to be treated in a superficial and ambiguous manner: "The anarchistic types are typical examples of that rebellious character and if they were transformed into adorers of power, little would be changed in them from a psychological view point. From this type of rebel one arrives, via various intermediary stages, at the type that abandons the person who had until then been the object of authority, only to submit simultaneously to a new authority. The cause of this can be seen both as resentment for unjust treatment or denial of love on the part of the old authority".

Resentment, disillusionment, love, and so on - these are psychological concepts that must also be examined within an essentially economic and political framework. Fromm does not seem to be unaware of this complexity, but even where he ought to introduce a sociological mode of analysis, he reverts back to a perfect symmetry between psychology and political action, and he inevitably asserts the primacy of the psychic over the economic. Indeed, I fail to see how he can avoid the pitfall of moralistic reasoning. Fromm writes: "This rebellion in which the object changes but the authoritarian structure remains intact and even is ultimately reinforced and whose ideal is the type of rebel who has acquired power, is sociologically of the greatest importance. Such rebellion can contain the seeds of 'revolution.' The new authority serves as a revolt against the former authority and increases the illusion that the struggle against the repressive authority is a struggle against repression in general. It could be, but the basic psychic structure is not modified, the revolt turns out to be a passing explosion of resentment and rebellion and the new authority occupies the position that the old one was no longer able to maintain."

The old and the new authority are, however, substantially equivalent. They are the simple, almost mechanical response to unchangeable and inescapable "impulses." Their transformation should not be interpreted as the rational outcome of a political project or an historical-economic program. It is only the expression of a basic ambivalence whose causal matrix lies in the very psychic constitution. I spoke of the 
role of "moralism" and of the reversal that this implies for any project whose aim is the rational transformation of traditional society. Beyond "moralism", which is a form of refined "scepticism", an iconoclastic cynicism like Pareto's begins to flourish. Indeed, the affirmation of the instinctive apparatus and of "impulses" from the unconscious is a step in that direction. From this perspective, history, i.e., the cumulative effect of human efforts within given economic and political circumstances, is reduced to a monotonous war between the weakened or declining power elites and the emerging elites, "new potential instances of authority," ready to scale the heights of power and, no less than the deposed ones, to use it for their own egoistic ends.

In his essay on authority in Studies in Critical Philosophy, Marcuse claims that Pareto "is the first writer in the monopoly phase of capitalism to deal with the psychological problem of class domination and even the first to put authority in a social context" Marcuse reconstructs in detail the relation between authority and the family found in the ideas of theorists from Luther and Calvin to Sorel and Pareto, by way of Kant, Hegel and Marx. He succeeds in revealing the real bond and structures of domination, and at the end of his own investigation he points out that the "psychic constant and its rationalization", inscribed in a "theory of social domination", are decisive in Pareto. Indeed, "all domination is based on coercion and on the rationalization of coercion, but that is not enough to guarantee the stability and continuity of domination : the more or less spontaneous consensus of the governed is necessary". According to Marcuse, Pareto saw more clearly than Sorel the importance of the family for maintaining and reproducing authority. While Sorel sees "the monogamous family as the administrator of the moral code of mankind", but he does not establish its connection with bourgeois society, Pareto's positivist analysis penetrates much more deeply into the dialectical substance of social reality. It is interesting to note how Marcuse's criticism of the "psychological" and "irrational" elements of Pareto's system could play against some proponents of the Frankfurt school, especially as regards their reliance on "determinate psychic mechanisms for the analysis and explanation of social phenomena". Indeed, this shows that, despite the formal distinction between positivism and idealism, the two are closely related.

The authors of Autorität und Familie sought to connect their theoretical claims with empirical investigations meant to provide the material necessary for empirical verification. The second part of the work is in fact dedicated entirely to this research. If the attempt is not completely successful, it is not due to theoretical errors in carrying out the study or to a lack of methodological skills, but mainly to the difficulty of the problems. The research could be superficially divided into three groups: a) a survey of workers and employees; b) a survey on sexual morals; and c) a survey among experts on authority and family. The questionnaires used show a modicum of formalization; the foreseen responses are almost all open, i.e., qualitative and not precodified. Neither 
calculation of correlations is attempted, nor it is possible to establish any connection between the variables considered particularly significant, even given the need to stress the relation between psychic and economic structures characterizing the social context. This last objective remains more a programmatic intent than anything else. It should come not as a surprise that the surveys do not produce substantial modifications of the basic proposition on sado-masochism presented in the "theoretical" essays written by Horkheimer, Fromm and Marcuse. The survey focuses on two groups of problems: authority as it constitutes one of the most important factors of social dynamics, and the family as it constitutes the social basis of personality formation. Given the imprecise nature of the technical tools used, the survey can legitimately be considered a pre-testing operation, essential for designing the questionnaire and weighting it according to the public and the interviewers. In the introductory note, Erich Fromm observes at length that with their emigration to the United States the collaborators of the Institute will be presented with the "opportunity to familiarize with the most advanced American methods of investigation".

It is difficult to say whether that opportunity is good or bad. The methods of social investigation in the United States seem traditionally to be tilted toward the psychological: in studying social phenomena, the tendency is to avoid both the economic and the political dimensions, not to mention the historical dimension, which is simply ignored. Thus social problems lose their objective firmness and are transformed into problems of interpersonal adaptation. Instead of being an essential instrument for the preliminary clarification of questions and for the positive advancement to their solution by means of changes in the socio-economic structure, sociological investigations in the United States are merely technical studies to obtain and confirm an a-critical mass conformism.

The study of psychology must be integrated with the analysis of the structural character and the economic and political dimensions of social phenomena, otherwise it falls into a psychological trap, which necessarily reduces the objective problems such as power relations into problems of pure states of mind and interpersonal relations. In addition to this, there is the tendency, so strong and typical among the scholars of the Frankfurt school, to avoid particular historical and political situations and to attempt instead a speculative analysis of a wide category of "domination" as such, separated from empirical investigation and indifferent to the economic and juridical structure. The need for a global study of problems that has constantly been advocated by the Frankfurt school is certainly valid, but since they attach less importance to specific field studies and since their theory posits an opposition between positivism and critical reflection, the globality they speak of risks being reduced to an empty traditional universalism as the end-point of a spurious totalization which has lost contact with the historically determined character of the structure. 


\section{The Eclipse of Reason}

In this perspective, the problems posed to humanity become insoluble, the liberty of the Enlightenment is transformed into its contrary, and the dream of an emancipated humanity gives way to a new barbarism. The very radical quality of denunciated evil acquires the tone and dimension of a new metaphysics. Horkheimer discovered the definitive words to express this despairing impasse: "If one were to speak of a disease affecting reason, this disease should be understood not as having stricken reason at some historical moment but as being inseparable from the nature of reason in civilization as we have known it so far. The disease of reason is that reason was born from man's urge to dominate nature...". ${ }^{16}$ The philosophical confirmation of this cruel self-accusation that reason pronounces against itself is seen most clearly in Horkheimer's The Eclipse of Reason. Here three separate and previously antagonistic spheres are brought in contact: reason, the subject, and nature. The attempt to dominate nature, to understand its secret and "laws" in order to subjugate it, required the establishment of an impersonal bureaucratic, "scientific" organization which in the name of victory over nature ended in reducing the human subject to a mere instrument. In this situation, the concept of formalized reason and the subject-object dialectic are necessary and inevitable results.

According to Horkheimer, the present crisis of reason "consists fundamentally in the fact that at a certain point thinking either became incapable of conceiving such objectivity at all or began to negate it as a delusion." ${ }^{17}$ The critical element sustaining the basic achievement of modem philosophy is the prolongation of a methodical skepticism that eats to the roots of the concept of truth and robs it of all meaning, transforming it into a merely subjective convention, formalized according to arbitrary limits: "The process was gradually extended to include the objective content of every rational concept. In the end, no particular reality can seem reasonable per se; all the basic concepts, emptied of their content, have come to be only formal shells. As reason is subjectivized, it also becomes formalized" ${ }^{18}$

It is not a question of the relation between the natural and the social sciences or of the cultural relation which was the crucial reference point of contemporary German thought and which generated the famous Methodenstreit in which writers such as Rickert, Windelband and Weber firmly opposed the possibility of a positivist analysis. Horkheimer's intention is different. "This book", he writes, "takes a different approach. Its aim is to inquire into the concept of rationality that underlies our contemporary industrial culture, in order to discover whether this concept does not

\footnotetext{
${ }^{16}$ M. Horkheimer, Eclipse of Reason, op.cit., p. 176

${ }^{17}$ Ibid., p. 7.

${ }^{18} \mathrm{lbid}$.
} 
contain defects that vitiate it essentially". ${ }^{19}$ The essential defect of reason today in technically progressive industrial society must be regarded, according to Horkheimer, as an operational transformation in which reason is at once artifex and victim. This consists in substituting the means for the ends and winds up by instrumentalizing reason itself in the very name of reason by reducing it to necessary, predictable and programmed thought, an integral part of the process of production. This shows that the Enlightenment has been turned into its direct opposite.

Enlightenment's individual liberty enters into crisis when change from an elastic to a mass culture is occurring alongside the transition from liberal, competitive capitalism to a capitalism dominated by an ever smaller number of large oligopolistic and monopolistic concentrations. Horkheimer approaches the problem both philosophically and socially: "Having given up autonomy, reason has become an instrument. In the formalistic aspect of subjective reason, stressed by positivism, its unrelatedness to objective content is emphasized; in its instrumental aspect, stressed by pragmatism, its surrender to heteronymous contents is emphasized. Reason has become completely harnessed to the social process. Its operational value, its role in the domination of men and nature, has been made the sole criterion". ${ }^{20}$

Domination is the truly universal at all-comprehensive category. But what kind of domination? It is no longer a personal domination of subjective ideas that have manipulated the world of anonymous domination, in pure flux, the consequence of decision arising from the instinct of self-preservation but filtered through a rational calculation that undermines the self and negates existence as the instinctive, inventive reaction to objective condition: "As the end result of the process, we have on the one hand the self, the abstract ego emptied of all substance except its attempt to transform everything in heaven and on earth into means for its preservation, and, on the other hand, an empty nature down degraded to mere material, mere stuff to be dominated, without any purpose than that of this very domination". ${ }^{21}$

Thus objective spirit, unprejudiced liberty of individual criticism that once was the basis of the justification and progressiveness of the Enlightenment, now has the same "obscurantist",regressive function of the objective reason of authoritarian religions and metaphysical philosophy. Horkheimer's criticism of individual subjective reason does not mean a return to dogmatic reason. On the contrary, it is a revolt against the desiccation of instincts, those essential impulses that have been so impoverished in the rational process. Without any concession to irrational tendencies, Horkheimer traces the trajectory which led from authoritarian and dogmatic religions to a complex of arbitrary, subjectivist constructions, incorporated into the manifestation of society

\footnotetext{
${ }^{19}$ Ibid, p. v.

${ }^{20}$ lbid, p. 21

${ }^{21}$ lbid, p. 97
} 
and new forms of domination. Horkheimer failed to provide us with its phenomenology, but he did produce a marvelous account of the stages in the proletarianization of the mind in the modern world.

\section{Total Bureaucratization and the Fate of the individual}

Horkheimer's criticism covers the entire range of modern thought from "neo-Thomism" to "neo-positivism". For Horkheimer instrumentality is not alien to the philosophical enterprise as such: "But the transition from objective to subjective reason was not an accident, and the process of development of ideas cannot arbitrarily at any given moment be reversed. If subjective reason in the form of enlightenment has dissolved the philosophical basis of beliefs that have been an essential part of Western culture, it has been able to do so because this basis proved to be too weak.

Their revival, therefore, is completely artificial: it serves the purpose of filling a gap. The philosophies of the absolute are offered as an excellent instrument to save us from chaos. Sharing the fate of all the doctrines, good or bad, that pass the test of present day social mechanisms of selection, objectivistic philosophies become standardized for specific uses. Philosophical ideas serve the needs of religious or enlightened, progressive or conservative groups. The absolute becomes itself a means, objective reason a scheme for subjective purposes, general as they may be". ${ }^{22}$

This criticism covers all of modern philosophy. But art? Isn't it possible through art to capture and express a meaning of reality not mediated by rational calculation and not preoccupied with relating ends and means, or as a consequence of utilitarian objectives?

Horkheirner's answer is negative: "Once it was the endeavor of art, literature, and philosophy to express the meaning of things and of life, to be the voice of all that is dumb, to endow nature with an organ for making known her sufferings, or we might say, to call reality by its rightful name. Today nature's tongue is taken away. Once it was thought that each utterance, word, cry, or gesture had an intrinsic meaning; today it is merely an occurrence". ${ }^{23}$

On the other hand, we can expect nothing from traditional philosophical reflection: "neo-Thomism" is futile; pragmatism can survive only to the extent that it proceeds to an ever greater and more coherent functionalizing of thought; "neo positivism", finally, pronounces a death sentence on scientific thinking. But science, which rises victorious from beneath the ruins of traditional philosophy, has nothing to say about the fundamental demand for a meaning of life, and the position of the individual in the world-questions that concern modern man. Proceeding from the formulation of

\footnotetext{
22 Ibid., p. 62.

${ }^{23}$ Ibid., p. 101.
} 
the hypothesis to the act of verification, it shows its cool neutrality, behind which may of course be hidden a constellation of interests or a political stratagem and even an aberration such as Nazism. But the fact that while dealing with dynamic principles science must also take multiple phenomena into account does not escape Horkheirner. Yet, whatever the modes of thought and the specific conceptions of scientific thinking may be, it cannot be forgotten that they are in fact auxiliary instruments of production. Beyond that, any scientific fact is an eminently social fact. From the wheel to anti-matter, all scientific facts are not solely relevant for science and indicate no superiority of scientism as a model for culture and society: "Like any existing creed, science can be used to serve the most diabolical social forces, and scientism is no less narrow-minded than militant religion". ${ }^{24}$ Horkheimer does not see clearly how, in the present of production, science becomes a directly productive force instead of being merely applied via the mediation of technology.

Thus his position must not be confused with Marcuse's, nor with that of apocalyptic authors who, by denouncing' science, really express the holy hope of a prompt return to the Middle Ages. For Horkheimer, science is not what can save humanity; rather in a free society, not fragmented and divided by objective contradictions of interests, science can attain an autonomous and coherent development: "Only under ideally harmonious conditions could progressive historical changes be brought about by the authority of science" ${ }^{25}$

But the present situation is far from harmonious and there is no easy consolation: "If one were to speak of a disease affecting reason, this disease should be understood not as having stricken reason at some historical moments, but as being inseparable from the nature of reason in civilization...Thus the derangement of reason goes far beyond the obvious malformation that characterizes it at the present time. Reason can realize itself only through reflecting on the disease of the world as produced and reproduced by men; in such self-critique, reason will at the same time remain faithful to itself by preserving and applying for no ulterior motive the principle of truth that we owe to reason alone". ${ }^{26}$

But is it possible for reason to go outside reason? Is it possible for culture to transcend culture? Is the self-awareness of reason sufficient to heal the ailment and cure the essential vice of domination? Is it not perhaps necessary, in the desire to avoid falling into dogmatic or metaphysical positions, to patiently explore that constellation of material interests and those objective contradictions of social life that Horkheimer considers as the crucial distortions of human life? Mass culture, the industrial society of the masses, atomization of the individual and his subjection to the impersonal

\footnotetext{
${ }^{24}$ Ibid., p. 71.

${ }^{25}$ Ibid, p. 83

${ }^{26}$ Ibid, p. 176-177.
} 
authorities of the administrative apparatus on a vast scale: all that does not stem from or affect just the intellectual plane, but it takes us to the objective conditions of the social process in its historical development.

These objective contradictions were not sufficiently treated by Horkheimer or by the members of the Frankfurt school. But if the questions raised by Horkheimer are squarely faced, then it must be recognized that he has brought them out in the open. Horkheimer criticized all abstractly philosophizing intellectuals. Yet, he himself remained a pure intellectual: concepts and empirical facts were not connected and the totalization resulted in a vacuous synthesis. The attempt failed, but it is hard not to admire the splendor of the failure. 